\title{
THE ANATOMY OF DISCOVERY
}

\section{From cot death to infant triggered ventilation}

\author{
Bernard Valman
}

\section{Cot death}

In 1974 two apparently normal infants diea suddenly and unexpectedly on the postnatal wards of our unit. In 1975 there were three sudden deaths and in 1976 four infants died in a similar way on the postnatal wards. Despite extensive investigation, including postmortem examination by the coroner's pathologist no cause was found. With one exception all these deaths occurred during the night. There were no other common features, although the following parameters were reviewed: standard of antenatal care, vaginal loss and infection, evidence of intrauterine growth retardation, anaemia, hospitalisation during pregnancy, management during pregnancy, and management of labour. Although expert advice had been taken previously, in 1976 I arranged a meeting with all the involved medical and nursing staff and invited speakers to determine the action to be taken. The second part of the meeting consisted of a workshop with selected members who included Dr David Tyrrell FRS, Professor John Emery, and Dr Martin Wright of the Bioengineering Division of the Clinical Research Centre. Methods of monitoring infants, especially at night, to detect early stages of illness were explored. As group B streptococci were causing a high mortality at that time and pneumonia was a common presenting feature,' Dr Wright was asked to devise a method of measuring respiratory rate without disturbing the sleeping infant in a postnatal ward.

\section{Respiration monitor}

Dr Wright had previously worked with Dr (later Professor) Jon Scopes at Hammersmith Hospital on the problem of apnoea alarms for premature babies. He observed that abdominal expansion gave a clear signal, and developed a miniature

Northwick Park Hospital and Clinical Research Centre, Harrow, Middlesex HA1 3UJ Correspondence to: Dr Valman.

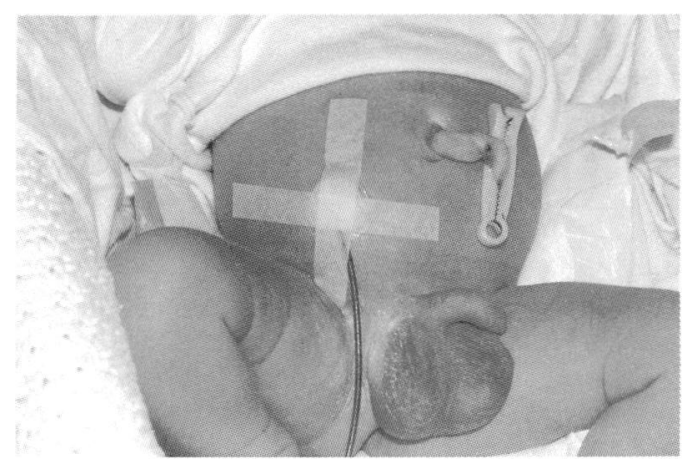

Figure I Capsule attached to abdomen.

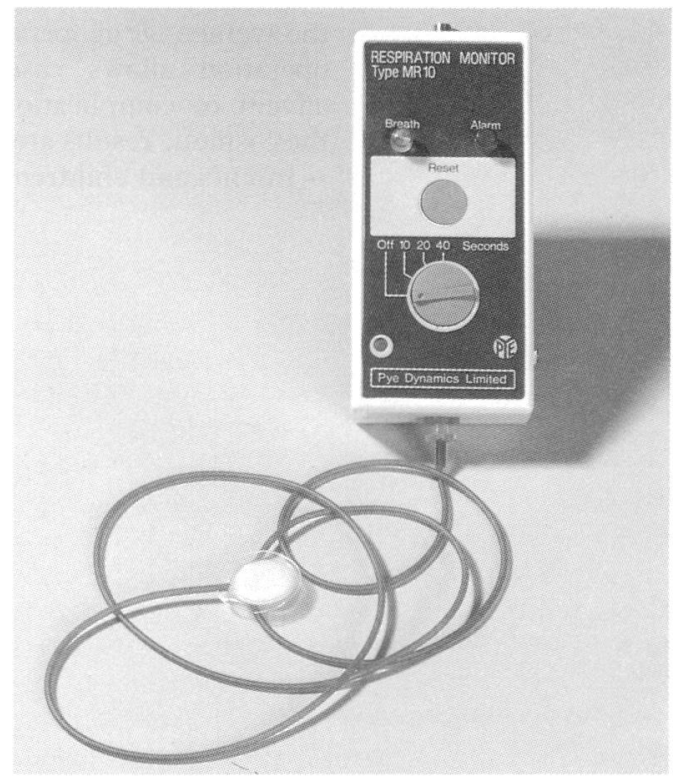

Figure 2 MR 10 with tube and capsule.

belt switch for detecting it. This proved too insensitive for use with the very small babies in the unit and the nurses disliked the use of the belt, so the method was abandoned in favour of the Lewin mattress. ${ }^{2}$ This device had been in use in the neonatal unit at Northwick Park but it was considered to be too clumsy and complicated for use in the postnatal wards. Dr Wright, assisted by $\mathrm{Mr}$ Kevin Callan, developed a new method of detecting respiration in which an air filled capsule was taped to the abdominal wall, so that the expansion of the abdomen compressed it and generated a pneumatic signal. This signal was carried along a flexible tube to a small hand held box in which it was converted to an electrical and then audible and visual signals. ${ }^{3}$ The sensor capsules were very simple and cheap so that one could be attached to each baby shortly after birth (fig 1), allowing the end of the tube to protrude from the cot. Each ward was supplied with a box which could be carried round by a nurse and connected to each baby in turn for counting the respiratory rate.

This device was extensively tested by Mrs Cathy Lawrence, the research sister, and found to be reliable and acceptable to nursing staff. ${ }^{+}$It was later produced commercially as the ' $\mathrm{MR} \mathrm{10}$ ' (fig 2) by Pye Dynamics (now Graseby Medical) and is in worldwide use as a respiration monitor in neonatal units. At the request of parents it has been used as an apnoea alarm at home for parents who had previously experienced a cot death. 


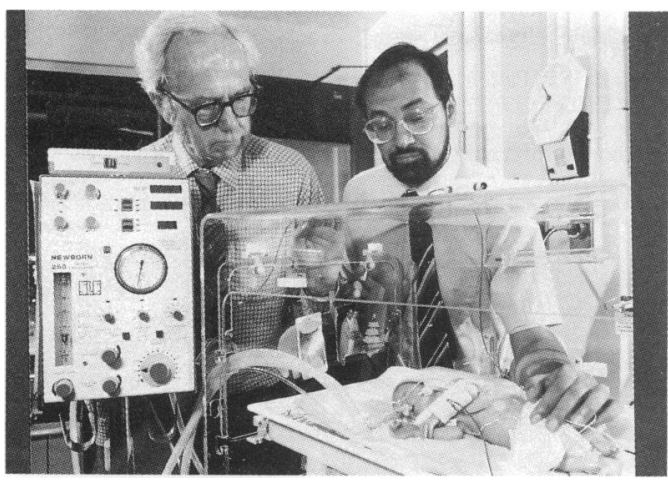

Figure 3 'Trigger box' on top of the ventilator. Dr Martin Wright is on the left and Dr Anil Mehta on the right.

Since that time infants on the postnatal wards in our unit have had measurements of respiratory rate at regular intervals and about $1 \%$ have a raised respiratory rate and have been transferred to the neonatal unit. Several cases of septicaemia have been detected in this ways but there have been no further unexpected deaths.

Incidently, the experience of respiratory rate monitoring at Northwick Park prompted David Tyrrell to recommend to the World Health Organisation the measurement of respiratory rate to distinguish between upper and lower respiratory tract infection in developing countries. ${ }^{6}$ The results have been reviewed recently. ${ }^{7}$

\section{Trigger ventilation}

In 1983 a baby of 26 weeks' gestation under my care who had been artificially ventilated for a prolonged period developed intermittent apnoeic attacks when he was extubated on three occasions. The respiratory rate then fell to about four per minute. The baby was monitored with a MR 10 which sounded the alarm whenever the apnoea lasted for more than five seconds. A single breath was then given by the nurse by pressing the manual button on the ventilator but this required constant nursing attention. The advantage of this approach was that the baby breathed spontaneously for most of the time. Dr Wright suggested that the MR 10 and the SLE ventilator should be electrically connected so that the single breath could be given automatically. This was done and worked well.

Dr Wright then realised that he had found a simple method of synchronising the ventilator with the baby's respiratory effort. Attempts to achieve it by detecting the pressure changes in the ventilator circuit had been abandoned for more than 10 years. ${ }^{8}$

Dr Anil Mehta undertook to test the system and quickly found that it was practicable and that ventilation was effective as judged by blood oxygen concentrations. The nursing staff were impressed as the baby appeared to be comfortable with no sedation or paralysis and could be weaned easily from the ventilator (fig 3). A paper was published after nine babies had been ventilated in this way." Dr Mehta continued to promote the method, helped and encouraged by Dr Rollo Clifford, the registrar, who continued after Dr Mehta left and was able to report that the incidence of pneumothorax in 103 ventilated babies had been reduced to zero. ${ }^{10}$

At first the method was thought to be unsuitable for the smallest infants, but it became apparent that even they could be successfully ventilated in this way if breathing was spontaneous. It has been the standard method of ventilating newborn infants in the unit since January 1987. The makers of the SLE ventilator took up the method and it began to be used in a number of other centres. Some of these units had difficulties with the method, chiefly those who were unfamiliar with the MR 10 and insisted on putting the capsule on or near the chest, where it was subject to paradoxical movements. ${ }^{11}$

\section{AIRWAYS PRESSURE TRIGGER VENTILATION}

Dr Wright left the Clinical Research Centre in 1988 for University College Hospital at the invitation of Professor Osmond Reynolds. Using more modern equipment he decided to investigate the possibility of airways pressure triggering, which had obvious advantages over the abdominal expansion method. It had been suggested that the method would not be effective because the very small signals could be lost in the 'noise' produced by the airflow through the expiratory valve.

Dr Wright found that with a modern strain gauge pressure transducer, which has ample sensitivity, and a pen recorder which filters out high frequency noise, he could obtain clear respiratory signals. He sent some recordings to $\mathrm{Mr}$ Michael Donovan of SLE plc, the maker of the ventilator, and asked him to make up a circuit to detect the signals and to trigger the ventilator. Some circuits were produced, but were clinically unsatisfactory and the trial was discontinued.

Dr Wright then asked Mr John Baker of the Bioengineering Division of the Clinical Research Centre to investigate the problem, and supplied him with a 'baby simulator' for testing purposes. Mr Baker produced a circuit that triggered the ventilator but when tested on the simulator could be seen to be firing half way through expiration instead of at the beginning of inspiration. ${ }^{12}$ A new ventilator has now been produced incorporating a correctly phased airways pressure trigger and successful long term ventilation using this method is described in the fetal and neonatal edition this month (page 308). ${ }^{13}$

I thank Dr Martin Wright who provided most of the detailed background to this paper and whose modesty prevented him from being a coauthor.

1 Cowen J, Gordon H, Sanderson PJ, Valman HB. Group B streptococcal infection in a maternity unit. $\mathrm{Br} \mathcal{F}$ Obste Gynaecol 1978; 85: 541-5.

2 Lewin JE. Apnoea-alarm mattress. Lancet 1969; ii: 667-8.

3 Wright BM, Callan K. A new respiration recording and monitoring system. Proceedings of the 3 rd world internationol symposium on ambulatory monitoring. London: Academic Press, 1980: 329-34.

4 Valman HB, Wright BM, Lawrence C. Measurement of respiratory rate in the newborn. $B M 71983 ; 286$ : 1783-4.

5 Mifsud A, Seal D, Wall R, Valman HB. Reduced neonatal mortality from infection after introduction of respiratory monitoring. BMF 1988; 296: 17-8.

6 World Health Organisation. Guidelines for research on acute respiratory infections: memorandum for a WHO meeting. Bull WHO 1982; 60: 521-33.

7 Berman S, Simoes EAF, Lanata C. Respiratory rate and pneumonia in infancy. Arch Dis Child 1991; 66: 81-4. 
8 Epstein RA. The sensitivities and response times of ventilatory assistors. Anesthesiology 1971; 34: 321-6.

9 Mehta A, Callan K, Wright BM, Stacey TE. Patient triggered ventilation in the newborn. Lancet 1986; ii: 17-9.

10 Clifford RD, Whincup G, Thomas R. Patient triggered ventilation prevents pneumothoraces in premature babies. ventilation prevents pne
Lancet 1988; i: 529-30.

11 Wright BM. Respiratory support using patient triggered ventilation in the neonatal period. Arch Dis Child 1992; 67: 885 .

12 Wright BM, Baker JA, Rosenthal M. Airways-pressure triggered (APT) ventilation in the newborn. Proceedings of the
physiological society. F Physiol (Lond) 1990; 426: 6 (abst).

13 de Boer R, Jones A, Ward PS, Baumer JH. Successful long term trigger ventilation in respiratory distress syndrome. Arch Dis Child 1993; 68: 308-11.

\section{Baby mathematicians}

Proposition: babies are endlessly fascinating people.

Proof: it has taken the human race 2 million years and literate mankind 5000 years to show that they can count to two.

We know babies are smart (see Archivist 1992: 1072) but how smart are they? For instance, are young babies able to appreciate number and to calculate change in number? Karen Wynn, a psychologist at the University of Arizona, believes they are. She did a series of three experiments (Nature 1992; 358: 749-50). In the first experiment she tested 32 normal babies aged 4 months 19 days to 5 months 16 days. Half of them were tested for addition (' $1+1$ group') and half for subtraction (' $2-1$ group'). The $1+1$ group were first shown a single item in a confined display area (the published illustration shows the 'item' to be a Micky Mouse type figure). A screen then rotated up to hide the item. Next the babies saw a hand appear from the side of the display area, place an identical second item behind the screen, and return empty. The screen then dropped to reveal either two items (expected) or one (unexpected). An observer measured the length of time the baby looked at the display after the screen dropped. In the 2-1 group the experiment started with two items on display and the hand was seen to remove one. Thus now when the screen dropped one item was expected and two unexpected. Babies' attention is attracted for longer to things they don't expect so the $1+1$ group would be expected to look longer at a single remaining item and the $2-1$ group at two remaining items if they were able to know how many items to expect. Each baby was shown the display six times with alternately one or two items revealed. Both groups looked longer at the 'impossible' result $(\mathrm{p}<0.05)$. In the second experiment the same procedure was repeated with 16 babies aged between 4 months 18 days and 5 months 5 days. The results were similar $(\mathrm{p}<0.05$ and combining experiments 1 and 2 , $\mathrm{p}<0.005)$.

These experiments showed that babies know that when you add or subtract an item something should change. Are they counting or simply looking for change? In a third experiment 16 babies aged between 4 months 4 days and 5 months 4 days were tested with a $1+1$ addition but when the screen went down they now saw either two or three items. Thus in both cases they saw a change but could they distinguish between the right change and the wrong one? They looked longer at the three items $(p<0.03)$, although when presented with either two or three items before the test they had preferred two.

Karen Wynn concludes that infants possess true numerical concepts and that her experiments suggest that human beings are innately endowed with mathematical abilities. 